\title{
Seasonality and determinants of moderate and severe COPD exacerbations in the
} TORCH study

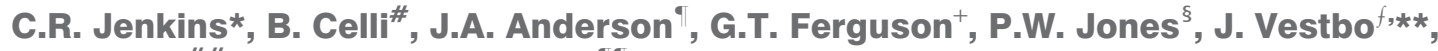 \\ J.C. Yates ${ }^{\# \#}$ and P.M.A. Calverley ${ }^{\text {ศब }}$
}

ABSTRACT: We investigated the impact of season relative to other determinants of chronic obstructive pulmonary disease (COPD) exacerbation frequency in a long-term international study of patients with forced expiratory volume in $1 \mathrm{~s}$ (FEV 1$)<60 \%$ predicted.

COPD exacerbations were defined by worsening symptoms requiring systemic corticosteroids and/or antibiotics (moderate) or hospital admission (severe). Seasonality effect was calculated as the proportion of patients experiencing an exacerbation each month.

Exacerbations in the northern and southern regions showed an almost two-fold increase in the winter months. No seasonal pattern occurred in the tropics. Overall, $38 \%$ of exacerbations were treated with antibiotics only, $19 \%$ with systemic corticosteroids only and $43 \%$ with both, while $20 \%$ required hospital admission irrespective of the season. Exacerbation frequency was associated with older age, lower body mass index, lower FEV $1 \%$ pred and history of prior exacerbations. Females and patients with worse baseline breathlessness, assessed using the Medical Research Council (MRC) dyspnoea scale, exacerbated more often (rate ratio (RR) for male versus female 0.7, 95\% Cl 0.7-0.8 ( $<<0.001)$; RR for MRC dyspnoea score 3 versus 1 and 2 combined $1.1,95 \% \mathrm{Cl}$ 1.1-1.2 $(p<0.001))$. The effect of season was independent of these risk factors.

COPD exacerbations and hospitalisations were more frequent in winter.

KEYWORDS: Chronic obstructive pulmonary disease, exacerbations, mortality, seasonal patterns, TORCH survival study

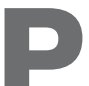

atients with moderate-to-severe chronic obstructive pulmonary disease (COPD) experience on average, two to three exacerbation episodes per year $[1,2]$. Hospitalisation and COPD-associated mortality account for substantial treatment and healthcare resource utilisation costs [2-4]. COPD exacerbations contribute to a worsening of health-related quality of life over time $[1,2,5]$ and their occurrence predicts the likelihood of dying [6].

Factors predicting the frequency and slow resolution of exacerbations include increasing age, more severe airflow obstruction and a history of prior exacerbations [7-10]. These data come from studies of differing size and duration of follow-up that reported annualised exacerbation rates. Less attention has been paid to the influence of time of year on exacerbation occurrence and management. There is evidence of a seasonal variation in the rate of hospital admissions for COPD, with more exacerbations occurring during the winter months compared with summer [11-13]. Exacerbations are also associated with cooler temperatures [14, 15]. This seasonal variation has been reported predominantly in countries in northern regions [16, 17], with little or no similar information available for either the southern regions or the tropics [18-20]. Furthermore, there is a paucity of information about seasonal variation in exacerbation rates and its importance compared with other factors predicting exacerbations. The current analysis was designed to test the impact of seasonal variation on reported exacerbations in relation to other risk factors, using data from the prospective, 3-yr Towards a Revolution in COPD Health (TORCH) study involving 6,112 patients from the northern and southern regions and the tropics [21].

\section{METHODS}

\section{Patients}

Outpatients aged 40-80 yrs with a diagnosis of COPD, defined in accordance with the European Respiratory Society (ERS) consensus statement [22], who were current or ex-smokers with $\geqslant 10$ packyrs smoking history were recruited. They had a
AFFILIATIONS

*Woolcock Institute of Medical Research, Camperdown, Australia. \#Pulmonary and Critical Care Division, Brigham and Women's Hospital, Harvard Medical School, Boston, MA,

+Pulmonary Research, Institute of Southeast Michigan, MI,

\#\#Respiratory Medicines Centre, GlaxoSmithKline, Research Triangle Park, NC, USA.

'Respiratory Medicines Centre, GlaxoSmithKline, Brentford

${ }^{5}$ Division of Cardiac and Vascular Science, St George's, University of London, London,

**North West Lung Centre, Wythenshawe Hospital, Manchester,

"Dept of Medicine, University Hospital Aintree, Liverpool, UK. ${ }^{f}$ Dept of Cardiology and Respiratory Medicine, Hvidovre Hospital, Denmark.

\section{CORRESPONDENCE}

C.R. Jenkins, Woolcock Institute of Medical Research, PO Box M77, Missenden Road, Camperdown,

Sydney NSW 2050, Australia

E-mail: crj@med.usyd.edu.au

\section{Received:}

Dec 162010

Accepted after revision:

May 202011

First published online: July 072011

European Respiratory Journal Print ISSN 0903-1936 Online ISSN 1399-3003 
pre-bronchodilator forced expiratory volume in $1 \mathrm{~s}$ (FEV1) of $<60 \%$ of predicted, with reversibility to $400 \mu \mathrm{g}$ salbutamol of $<10 \%$ of predicted FEV1 and a FEV1/forced vital capacity ratio of $\leqslant 70 \%$ after bronchodilator. Exclusion criteria have been described previously [21] and included long-term oxygen therapy at start of the study, or an exacerbation requiring systemic corticosteroids or hospitalisation during the run-in period.

\section{Study design}

TORCH was a multicentre, randomised, double-blind, parallelgroup, 3-yr study conducted in 42 countries around the world [21]. Eligible patients were stratified by smoking status and were randomised to receive placebo, $50 \mu \mathrm{g}$ salmeterol, $500 \mu \mathrm{g}$ fluticasone propionate or $50 / 500 \mu \mathrm{g}$ salmeterol/fluticasone propionate combination via the Diskus ${ }^{\mathrm{TM}} /$ Accuhaler $^{\mathrm{TM}}$ inhaler (GlaxoSmithKline, London, UK) (one inhalation twice daily) for 3 yrs. All patients visited the clinic at 12-weekly intervals; during these visits, specific enquiries were made regarding exacerbations or events that required a change in treatment or hospitalisation by asking the standard questions "Have you had any (other) medical problems since your last visit/assessment?" and "Have you taken any new medications, other than those given to you within this study since your last visit/assessment?" Exacerbations were recorded as moderate (defined by worsening symptoms requiring treatment with antibiotics and/ or systemic corticosteroids) or severe (defined as those requiring hospitalisation), and were documented by the investigator as an adverse event or serious adverse event. Treatment with short courses of systemic corticosteroids and/or antibiotics as reported by the patient was recorded on the patient's case report form. All patients gave written informed consent, and the study was approved by local ethical review boards and conducted in accordance with the Declaration of Helsinki and Good Clinical Practice guidelines.

\section{Statistical analysis}

The number of patients reporting a new exacerbation was expressed as a proportion of the patients on treatment during the month in which the exacerbation started. The pattern of exacerbations was analysed according to geographical location, based on the locations of the participating centres. Similar analyses were conducted for all deaths occurring during the 3-yr study period. Study populations were grouped into the northern region (Canada, China, 26 eastern and western European countries, and the USA), the southern region (Argentina, Australia, Brazil, Chile, New Zealand and South Africa) and the tropics (countries lying between the tropics of Capricorn and Cancer: Hong Kong, Malaysia, Mexico, Philippines, Singapore, Taiwan and Thailand).

For seasonal comparisons, in the northern region, we defined summer as June to August inclusive and winter as December to February, with the reverse for the southern region. Recruitment began in September 2000 and the study ended in November 2005. Our investigation of seasonality of exacerbations was restricted to a 4-yr period (April 2001 to March 2005) when sufficient numbers of patients were on treatment to reduce the amount of random variation. For all other analyses, all data were used.
The number of exacerbations experienced by a patient during the study was expressed as a rate per year to account for the differing times on treatment. Exploratory analysis of the association between exacerbation rates during treatment and baseline characteristics was performed by modelling the exacerbation rates using the negative binomial distribution (to account for patient variability), using the logarithm of time on treatment as an offset variable. Smoking status, sex, region, treatment, exacerbations in the year prior to study entry (as recalled retrospectively by the patients or investigators at study entry), body mass index (BMI), Medical Research Council (MRC) dyspnoea score, age and baseline FEV1 \% pred were included in the model. Rate ratios (RR) with 95\% confidence intervals were calculated for each covariate with all other covariates included in the model.

\section{RESULTS}

Demographic and baseline characteristics of the study population are shown in table 1 . Mean \pm SD age was $65 \pm 8$ yrs and post-bronchodilator FEV1 was $1.23 \pm 0.4$ L. Males comprised the majority of the study population and $>40 \%$ of all patients were current smokers. Nearly $60 \%$ of patients had at least one exacerbation in the year prior to study entry; half of these had two or more exacerbations.

$79 \%$ of the study population was recruited from the northern region, $10 \%$ from the southern region and $11 \%$ from the tropics.

\section{Overall rates of exacerbations}

Overall exacerbation rates per year (moderate or severe) are shown in figure 1 . The distribution was highly skewed; the majority of patients had between no and two exacerbations per year, but a few had much higher rates. In total, there were $\sim 13,000$ exacerbations. The annual rate for moderate or severe exacerbations was 1.13 in the placebo group, 0.97 in the $50 \mu \mathrm{g}$ salmeterol group, 0.93 in the $500 \mu \mathrm{g}$ fluticasone propionate group and 0.85 in the $50 / 500 \mu \mathrm{g}$ salmeterol/fluticasone propionate group.

\section{Pattern of new exacerbations}

In the northern and southern regions, but not the tropics, a seasonal pattern of exacerbations was seen, with a higher proportion of patients exacerbating in the winter months, which was consistent over the 4 -yr period. Figure $2 \mathrm{a}$ and $\mathrm{b}$ shows the raw data of the proportion of patients exacerbating in each month for the northern and southern regions and the tropics, respectively. Figure $2 \mathrm{c}$ and $\mathrm{d}$ represents the same information averaged into one calendar year. The pattern of exacerbations in the northern region was mirrored by the pattern of exacerbations in the southern region (fig. 2a and c). A higher proportion of patients in the southern region reported an exacerbation in any seasonally adjusted month compared with the northern region (fig. 2c). In the northern region, $5 \%$ of patients reported an exacerbation in the summer compared with $9 \%$ in the winter, while in the southern region, $7 \%$ of patients reported an exacerbation in the summer compared with $12 \%$ in the winter (fig. $2 \mathrm{c}$ ). This seasonal pattern was seen in all four treatment arms.

\section{Management of exacerbations}

The proportion of patients with exacerbations treated with systemic corticosteroids alone, antibiotics alone or both in the northern and southern regions is presented in figure 3. 


\begin{tabular}{|c|c|c|c|c|}
\hline & ITT (efficacy) & Northern & Southern & Tropics \\
\hline Age yrs & $65.0 \pm 8.3$ & $64.8 \pm 8.3$ & $65.5 \pm 8.5$ & $66.5 \pm 7.3$ \\
\hline Males \% & 76 & 75 & 72 & 89 \\
\hline Post-bronchodilator FEV $1 \%$ pred & $44.3 \pm 13.4$ & $45.1 \pm 13.2$ & $42.4 \pm 13.2$ & $40.3 \pm 14.3$ \\
\hline Reversibility \% pred FEV 1 & $3.7 \pm 3.7$ & $3.6 \pm 3.8$ & $4.0 \pm 3.5$ & $3.5 \pm 3.7$ \\
\hline $\mathrm{BMI} \mathbf{k g} \cdot \mathrm{m}^{-2}$ & $25.4 \pm 5.2$ & $26.0 \pm 5.1$ & $24.6 \pm 4.9$ & $21.7 \pm 4.1$ \\
\hline Exacerbation rate ${ }^{\#}$ & $1.2 \pm 1.6$ & $1.2 \pm 1.5$ & $1.2 \pm 1.6$ & $1.6 \pm 2.3$ \\
\hline 0 exacerbations \% & 43 & 43 & 42 & 40 \\
\hline 1 exacerbation \% & 25 & 25 & 24 & 24 \\
\hline
\end{tabular}

Data are presented as mean \pm SD, unless otherwise stated. ITT: intention to treat; FEV1: forced expiratory volume in $1 \mathrm{~s} ; \%$ pred: \% predicted; BMI: body mass index. ${ }^{\#}$ : in the 12 months prior to study entry.

Overall, 38\% of exacerbations were treated with antibiotics only, $19 \%$ with systemic corticosteroids only and $43 \%$ with both. In the northern region, more exacerbations in the winter $(43 \%)$ were treated with antibiotics compared with those in the summer $(37 \%)$. This pattern was reversed for exacerbations treated with systemic corticosteroids (15\% in winter but $24 \%$ in summer). A clear seasonal treatment pattern was not seen in the southern region, possibly due to the smaller number of patients.

The proportion of all patients who required hospitalisation for exacerbation in any given month was higher in the winter. For instance, in the northern region, the highest proportion, in December $(1.9 \%)$, was double that reported in the lowest month (August; 0.9\%). However, the proportion of exacerbations requiring hospitalisation was similar year-round, with a summer mean of $18.3 \%$ and a winter mean of $18.8 \%$. This pattern was similar in the southern region, but different in the

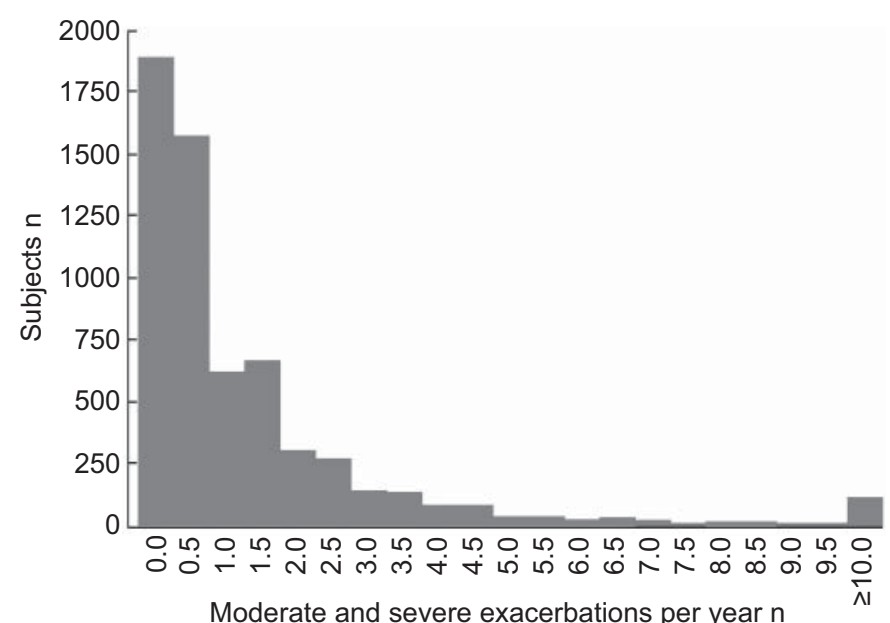

FIGURE 1. Distribution of exacerbation rates per patient per year during the study. The very high calculated exacerbation rates $(\geqslant 10)$ were primarily due to premature drop-out of frequent exacerbators with $<6$ months follow-up time. tropics, with a higher proportion of events requiring hospitalisation $(31.2 \%)$ than in the other regions $(18.3 \%$ in the northern region and $15.7 \%$ in the southern region). Across all regions $20 \%$ of exacerbations required hospitalisation.

\section{Factors affecting exacerbation rates}

The effect of covariates on the rate of exacerbations during the study is shown in table 2. Season was a significant covariate with respect to exacerbation rate. In northern and southern regions, there were more exacerbations in the winter compared with the summer. Patients $\geqslant 75$ yrs of age, compared with patients $<55$ yrs of age, had $20 \%$ more exacerbations (RR 1.2, $95 \%$ CI 1.0-1.3; $p=0.023$ ). Compared with patients with a mean BMI of 20 to $<25 \mathrm{~kg} \cdot \mathrm{m}^{-2}$ at baseline, patients with a BMI of $\geqslant 29 \mathrm{~kg} \cdot \mathrm{m}^{-2}$ had $10 \%$ fewer exacerbations (RR 0.9, 95\% CI 0.8-0.9; p<0.001), while a low BMI $\left(<20 \mathrm{~kg} \cdot \mathrm{m}^{-2}\right)$ was associated with a $10 \%$ increased rate of exacerbations (RR 1.1, 95\% CI 1.0-1.2; $\mathrm{p}=0.241$ ).

Low FEV1 was also associated with an increased rate of exacerbation (FEV1 $<30$ compared with $\geqslant 50 \%$ pred: RR 1.9 , 95\% CI $1.7-$ $2.1 ; \mathrm{p}<0.001)$. Patients who reported one exacerbation in the year prior to study entry had a 50\% higher rate of exacerbations while on treatment (RR 1.5, 95\% CI 1.4-1.6; p<0.001) and those reporting two or more exacerbations in the year prior to study entry had nearly double the rate (RR 1.9, 95\% CI 1.8-2.1; p <0.001) compared with patients who reported no exacerbations.

Males had a $30 \%$ lower exacerbation rate than females (RR 0.7, $95 \%$ CI 0.7-0.8; p < 0.001). Increasing severity of dyspnoea, based on baseline MRC dyspnoea grade, was associated with a greater rate of exacerbations, a grade of 3 having an exacerbation RR of 1.1 (95\% CI 1.1-1.2; $\mathrm{p}<0.001)$ and grades 4 and 5 having a RR of $1.3(95 \%$ CI 1.2-1.4; $\mathrm{p}<0.001)$, compared with grades 1 and 2.

Current smoking was associated with a $10 \%$ lower rate of reported exacerbations than former smoking (0.9 RR, 95\% CI $0.8-0.9 ; \mathrm{p}<0.001)$, after adjusting for other covariates.

The reporting of exacerbations differed according to region, with the rate in the northern region being $20 \%$ lower than in the southern region (RR 0.8, 95\% CI 0.7-0.9; $\mathrm{p}<0.001$ ). 

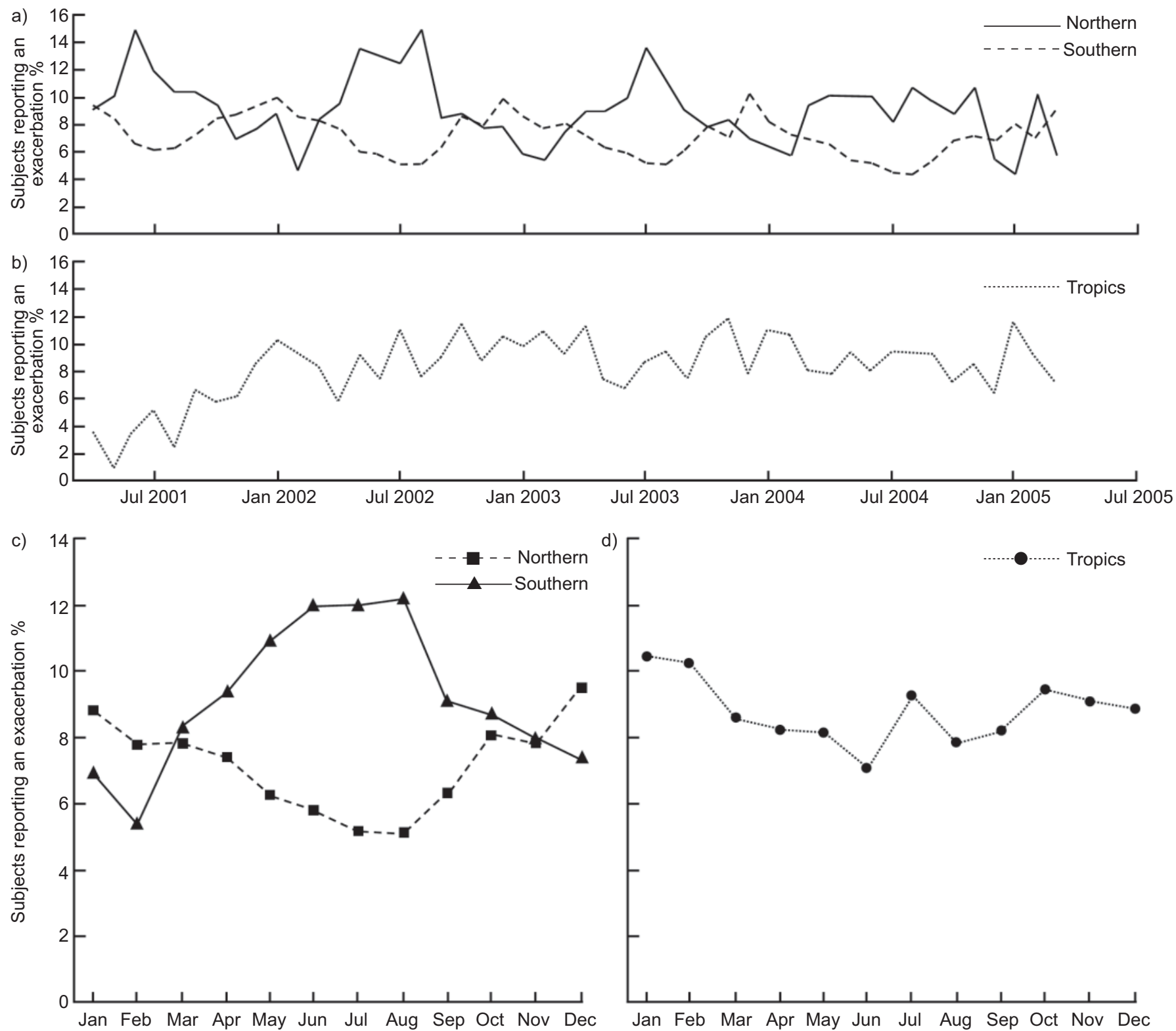

FIGURE 2. Proportion of patients reporting an exacerbation in the a) northern and southern regions and b) tropics over 4 yrs, and reporting an exacerbation in the c) northern and southern regions and d) tropics averaged over one calendar year.

The seasonal influence on exacerbation pattern was evident in all the patient subgroups studied. This is illustrated in figure 4 for FEV1 \% pred and MRC dyspnoea grade.

\section{Mortality}

There were more deaths in the 3 months of winter than the 3 months of summer. In the northern region, 625 of the 4,849 patients died and 180 (29\%) of these deaths occurred during the 3 months of winter in the 3-yr study period, while 135 $(22 \%)$ occurred in the summer. In the southern region 113 of the 622 patients died, $42(37 \%)$ during winter compared with $16(14 \%)$ during the summer.

These differences in seasonal mortality were more evident for COPD-related deaths, which accounted for $41 \%$ of all deaths in
TORCH. In the northern region, 79 (34\%) of the 235 COPDrelated deaths occurred during winter while 48 (20\%) occurred in the summer. In the southern region, 27 (55\%) of these deaths occurred during winter and four $(8 \%)$ during the summer.

\section{DISCUSSION}

COPD patients and their doctors know that exacerbations occur commonly in the winter months, but data to establish the size of this effect have been lacking. Exacerbations defined by healthcare use, as proposed recently by the American Thoracic Society (ATS)/ERS task force [23], were more common during winter. These patterns were consistent from year to year over the study period and accounted for an almost two-fold increased risk of exacerbation in winter, in northern and southern region countries, but not in the tropical countries. 

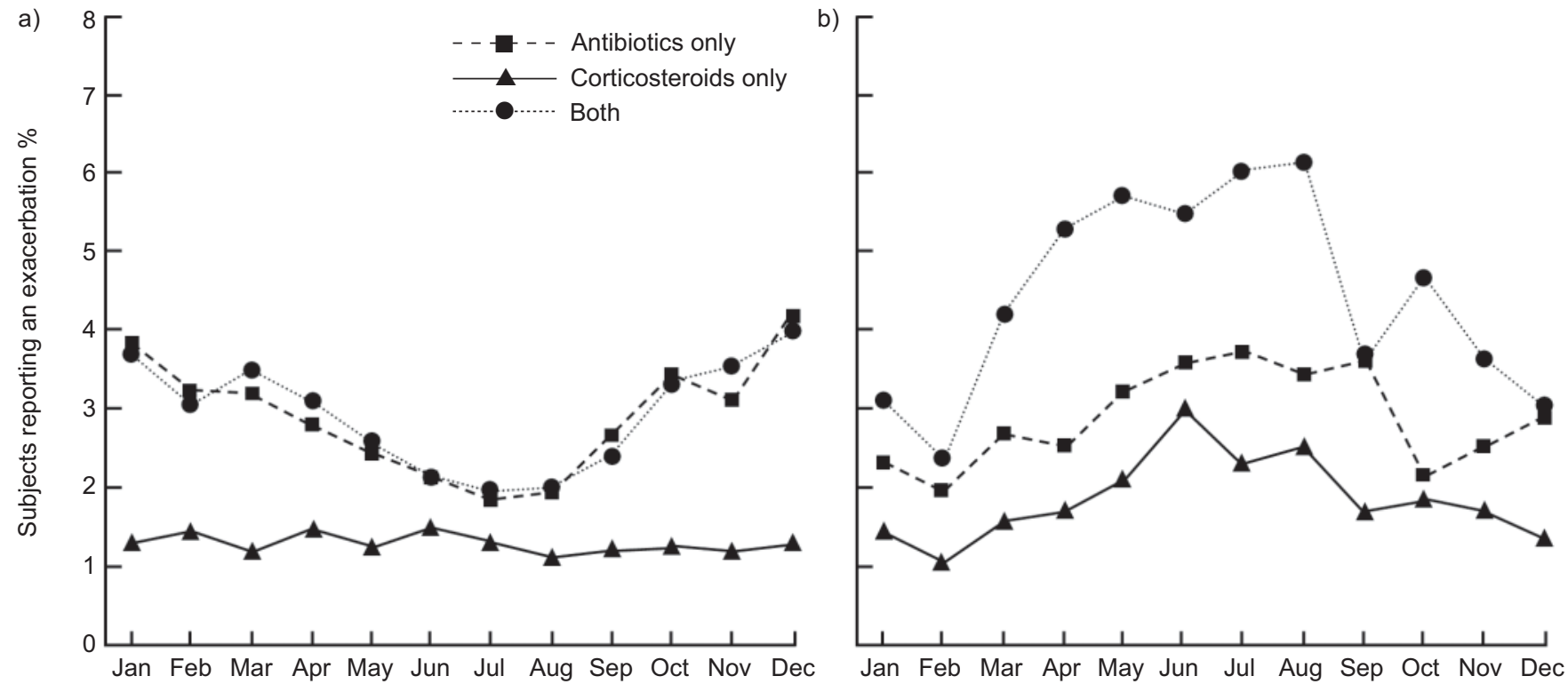

FIGURE 3. Proportion of patients reporting an exacerbation and treatment received in the a) northern and b) southern regions.

\begin{tabular}{|c|c|c|}
\hline Factor & $\operatorname{RR}(95 \% \mathrm{Cl})$ & p-value \\
\hline \multicolumn{3}{|l|}{ Smoking status } \\
\hline Current versus former & $0.9(0.8-0.9)$ & $<0.001$ \\
\hline Age yrs & & 0.064 \\
\hline 55-64 versus $<55$ & $1.1(1.0-1.3)$ & 0.012 \\
\hline $65-74$ versus $<55$ & $1.1(1.0-1.3)$ & 0.020 \\
\hline$\geqslant 75$ versus $<55$ & $1.2(1.0-1.3)$ & 0.023 \\
\hline Post-bronchodilator FEV $1 \%$ pred & & $<0.001$ \\
\hline$<30 \%$ versus $\geqslant 50 \%$ & $1.9(1.7-2.1)$ & $<0.001$ \\
\hline 30 to $<50 \%$ versus $\geqslant 50 \%$ & $1.4(1.3-1.5)$ & $<0.001$ \\
\hline \multicolumn{3}{|l|}{ Sex } \\
\hline Male versus female & $0.7(0.7-0.8)$ & $<0.001$ \\
\hline $\begin{array}{l}\text { COPD exacerbations in the previous } \\
\text { year }\end{array}$ & & $<0.001$ \\
\hline 1 versus 0 & $1.5(1.4-1.6)$ & $<0.001$ \\
\hline$\geqslant 2$ versus 0 & $1.9(1.8-2.1)$ & $<0.001$ \\
\hline $\mathrm{BMI} \mathbf{k g} \cdot \mathrm{m}^{-2}$ & & $<0.001$ \\
\hline$<20$ versus 20 to $<25$ & $1.1(1.0-1.2)$ & 0.241 \\
\hline 25 to $<29$ versus 20 to $<25$ & $1.0(0.9-1.0)$ & 0.262 \\
\hline$\geqslant 29$ versus 20 to $<25$ & $0.9(0.8-0.9)$ & $<0.001$ \\
\hline MRC dyspnoea grade & & $<0.001$ \\
\hline 3 versus $1+2$ & $1.1(1.1-1.2)$ & $<0.001$ \\
\hline $4+5$ versus $1+2$ & $1.3(1.2-1.4)$ & $<0.001$ \\
\hline Region & & $<0.001$ \\
\hline North versus south & $0.8(0.7-0.9)$ & $<0.001$ \\
\hline Tropics versus south & $0.9(0.8-1.0)$ & 0.045 \\
\hline
\end{tabular}

Rate ratios (RR) with 95\% confidence intervals were calculated for each covariate with all other covariates included in the model. Multivariate negative binomial model (each variable adjusted for all the others). FEV1: forced expiratory volume in $1 \mathrm{~s}$; \% pred: \% predicted; COPD: chronic obstructive pulmonary disease; BMI: body mass index; MRC: Medical Research Council.
Thus far, data supporting a seasonal pattern in COPD exacerbations have been derived from smaller studies conducted mainly in Europe [12-14, 16, 17], where a seasonal effect has been reported as part of other analyses. The TORCH study population comprises data collected over 3 yrs from patients in 42 countries and, as such, provides sufficient power to extend and support the previously reported findings. COPD hospital admissions and deaths increase dramatically in the winter months, as do general practice visits for respiratory tract infections [14-17]. Factors potentially contributing to this include increased exposure to viral infections, increased host susceptibility, greater time spent indoors, reduced physical activity and temperature-related reduction in lung function. These patterns also relate to lower weekly mean temperatures, as well as influenza activity and personal cold exposure factors [24]. The mechanisms by which a greater risk of respiratory infections occurs in winter are complex, and include the interaction of temperature and humidity, changes in human behaviour, exposure to colder air indoors and outdoors [14-17, 25-28], air pollution, and greater vulnerability of the local host defence [20, 29].

The seasonal variation was not seen in tropical countries that are characterised by relatively constant temperatures, with a mean of $\geqslant 18^{\circ} \mathrm{C}\left(\geqslant 64^{\circ} \mathrm{F}\right)$, all year round. In tropical regions, there is background influenza activity throughout the year $[30,31]$, which may contribute to a more stable pattern of exacerbations throughout the year, as noted in the present study. Seasonal variations occur with some infections in the tropics, but may be more closely related to the wet season, air pressure and relative humidity rather than temperature alone $[17,18,20]$. Other factors include outdoor pollution [30-32] and its interaction with cooler temperatures. The tropical countries in TORCH differ in distance from the equator and meteorological characteristics, which produce different seasonal patterns of respiratory illness between countries [33].

The seasonal variation in the number of exacerbation events was accompanied by a variation in the treatment of exacerbations. 

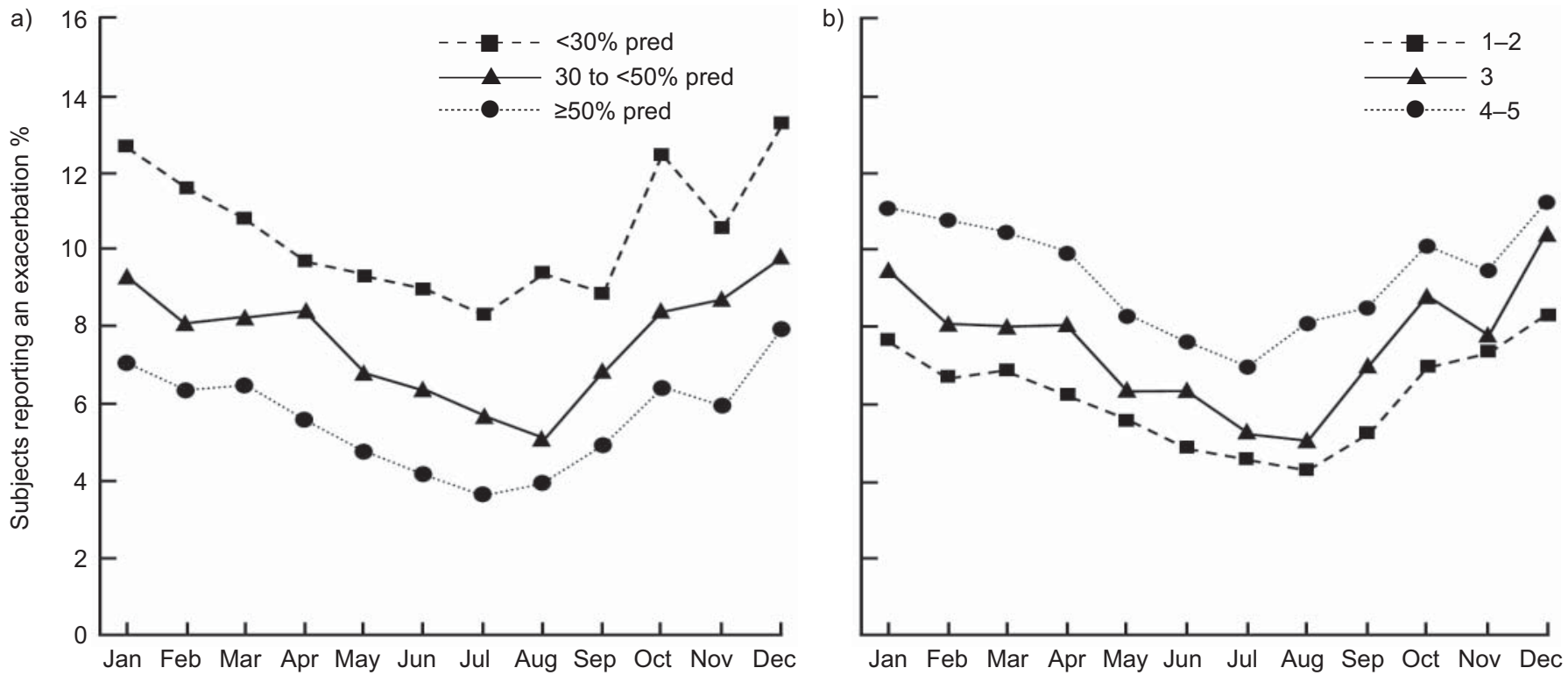

FIGURE 4. Proportion of patients reporting an exacerbation in the northern region by a) forced expiratory volume in $1 \mathrm{~s}$ and b) Medical Research Council dyspnoea grade. \% pred: \% predicted.

Antibiotics were used alone or in combination with steroids more frequently in the winter months compared with summer in the northern region. The treatment difference may reflect differences in the way exacerbation patients present in the winter, but data about seasonal variation in the microbiology of COPD patients are lacking. In contrast, in the southern region, both antibiotic and systemic corticosteroid use increased in the winter, and there was a strong tendency for both to be used in combination. The reason for these differences cannot be determined here and requires further study.

More patients were hospitalised due to COPD in the winter months, although, in absolute terms, the proportion of cases where this occurred was low. However almost $20 \%$ of exacerbations in our large, worldwide population required hospitalisation, and this was consistent between the seasons and very similar to that reported in a smaller US study [34]. Moreover, the relative proportion of events leading to hospital admission was unaffected by season, suggesting that the colder weather increased the number, rather than the overall severity, of exacerbations.

Like other researchers, we found that older age, having a lower $\mathrm{BMI}$, a lower FEV1 and a higher incidence of exacerbations in the previous year all significantly increased the risk of exacerbations [7-10]. In addition, we found that sex and MRC dyspnoea grade at study entry, and smoking status are risk factors. Females report more breathlessness for similar levels of airflow obstruction and are more likely to receive treatment for COPD than males $[35,36]$. They may, therefore, be more likely to be classified as having an exacerbation. However, there are also data indicating that females are at higher risk of being hospitalised for exacerbations [37], which is unlikely to be due solely to differential symptom reporting. A higher MRC dyspnoea grade may identify patients more likely to receive exacerbation treatment when they present with worsening symptoms. However, MRC grade also relates to exercise performance and the degree of activity normally undertaken is a predictor of the risk of exacerbation $[7,38]$. The paradoxical observation that current smokers were less likely to exacerbate than ex-smokers may not be a chance finding. Potential explanations may be a healthy survivor effect or the possible beneficial effect of smoking on sputum clearance [39, 40].

Our data differ in the magnitude of some of the associations from those reported by HuRsT et al. [10] for the Evaluation of COPD Longitudinally to Identify Predictive Surrogate EndPoints (ECLIPSE) study. We identified almost twice as many exacerbations as that observational study, which included more patients with moderate COPD, who were taking more medication than in our clinical patient population. Moreover, our study was not confined to Europe, North America and New Zealand and, unlike ECLIPSE, we did not record the presence of reflux symptoms. While these factors help explain some of the differences in predictive capacity, it is reassuring to see the considerable agreement in the determinants of exacerbation risk, irrespective of the composition of the study population. Notably, the seasonal effect on exacerbations occurred independently of all the identified risk factors.

Winter mortality from pre-existing respiratory disease was the single strongest predictor of excess deaths in a large general practice-based UK study [41] and pre-existing respiratory disease increased mortality from cardiovascular but not respiratory causes. Several other studies have demonstrated excess allcause, cardiovascular and respiratory mortality in winter, which is greater in females than males [25-27]. Somewhat paradoxically, vulnerability to death is increased to a greater extent for a given fall of temperature in regions with warmer winter temperatures. This appears to relate to greater personal cold exposure, lack of indoor heating, failure to dress appropriately for the cold and reduced outdoor physical activity [27, 28]. In our population, possibly due to the limited number of events, especially in the southern region, we did not see a clear seasonal pattern in mortality. 
There are strengths and limitations of our data. We recorded data in a standardised way in a large patient population and carefully identified the time and cause of death [42]. This approach provided adequate statistical power to test for differences due to region or risk factors. Although we excluded subjects with known serious comorbidities, including those dependent on oxygen therapy at entry, we do not believe the study population and setting bias our main findings. We recognise that ours was a treatment intervention trial and not an epidemiological study, and acknowledge the inherent differences between these two study types. However, the lack of interaction between any of the treatments used in this study and the factors identified as predicting exacerbation allowed us to pool all the data for this analysis, enabling analysis from $>6,000$ patients.

\section{Conclusion}

In the TORCH trial, the major burden of exacerbations fell in the winter months of both northern and southern regions of the world, which aligns with the perceptions of COPD patients and their doctors. Furthermore, the risk factors identified in this study (which, it must be considered, was an interventional study) may make it possible to prospectively profile an individual's risk of exacerbating and, thus, allow optimisation of care to reduce this risk. Further studies to establish the feasibility of such an approach are warranted.

\section{SUPPORT STATEMENT}

This study was funded by GlaxoSmithKline (study code SCO30003).

\section{CLINICAL TRIAL}

This study is registered at www.clinicaltrials.gov with identifier number NCT00268216.

\section{STATEMENT OF INTEREST}

Statements of interest for all authors and for the study itself can be found at www.erj.ersjournals.com/site/misc/statements.xhtml

\section{ACKNOWLEDGEMENTS}

Editorial support, in the form of development of the draft outline, editorial suggestions to draft versions of this paper, assembling tables and figures, collating author comments, copy editing, fact checking, referencing and graphic services was provided by D. Cutler (GardinerCaldwell Communications, Macclesfield, UK) and was funded by GlaxoSmithKline.

\section{REFERENCES}

1 Miravitlles M, Ferrer M, Pont A, et al. Effect of exacerbations on quality of life in patients with chronic obstructive pulmonary disease: a 2 year follow up study. Thorax 2004; 59: 387-395.

2 Donaldson GC, Wedzicha JA. COPD exacerbations. 1. Epidemiology. Thorax 2006; 61: 164-168.

3 Chapman KR, Mannino DM, Soriano JB, et al. Epidemiology and costs of chronic obstructive pulmonary disease. Eur Respir J 2006; 27: 188-207.

4 Lopez AD, Shibuya K, Rao C, et al. Chronic obstructive pulmonary disease: current burden and future projections. Eur Respir J 2006; 27: 397-412.

5 Seemungal TAR, Donaldson GC, Paul EA, et al. Effect of exacerbation on quality of life in patients with chronic obstructive pulmonary disease. Am J Respir Crit Care Med 1998; 157: 1418-1422.
6 Soler-Cataluna JJ, Martinez-Garcia MA, Sanchez PR, et al. Severe acute exacerbations and mortality in patients with chronic obstructive pulmonary disease. Thorax 2005; 60: 925-931.

7 Garcia-Aymerich J, Farrero E, Felez MA, et al. Risk factors for readmission to hospital for a COPD exacerbation: a prospective study. Thorax 2003; 58: 100-105.

8 Kessler R, Faller M, Fourgaut G, et al. Predictive factors of hospitalization for acute exacerbation in a series of 64 patients with chronic obstructive pulmonary disease. Am J Respir Crit Care Med 1999; 159: 158-164.

9 Seemungal TA, Donaldson GC, Bhowmik A, et al. Time course and recovery of exacerbations in patients with chronic obstructive pulmonary disease. Am J Respir Crit Care Med 2000; 161: 1608-1613.

10 Hurst JR, Vestbo J, Anzueto A, et al. Susceptibility to exacerbation in chronic obstructive pulmonary disease. N Engl J Med 2010; 363: $1128-1138$.

11 Johnston NW. The similarities and differences of epidemic cycles of chronic obstructive pulmonary disease and asthma exacerbations. Proc Am Thorac Soc 2007; 4: 591-596.

12 Bryden C, Bird W, Titley HA, et al. Stratification of COPD patients by previous admission for targeting of preventative care. Respir Med 2009; 103: 558-565.

13 de la Iglesia Martinez F, Pellicer Vazquez C, Ramos Polledo V, et al. Chronic obstructive pulmonary disease and the seasons of the year. Arch Bronconeumol 2000; 36: 84-89.

14 Donaldson GC, Seemungal T, Jeffries DJ, et al. Effect of temperature on lung function and symptoms in chronic obstructive pulmonary disease. Eur Respir J 1999; 13: 844-849.

15 Dowell SF, Ho MS. Seasonality of infectious diseases and severe acute respiratory syndrome - what we know can't hurt us. Lancet Infect Dis 2004; 4: 704-708.

16 Wilkinson P, Patenden S, Armstrong B, et al. Vulnerability to winter mortality in elderly people in Britain: population based study. BMJ 2004; 329: 647-650.

17 Bryden C, Bird W, Halpin DM, et al. Seasonality in chronic obstructive pulmonary disease emergency admissions to hospital, and predictability using surveillance for influenza-like illness. Thorax 2006; 61: Suppl. 2, S079.

18 Shek LP, Lee BW. Epidemiology and seasonality of respiratory tract infections in the tropics. Paediatr Respir Rev 2003; 4: 105-111.

19 Chew FT, Dorasingham S, Ling AE, et al. Seasonal trends of viral respiratory tract infections in the tropics. Epidemiol Infect 1998; 121: 121-128.

20 Dowell SF. Seasonal variation in host susceptibility and cycles of certain infectious diseases. Emerging Infect Dis 2001; 7: 369-374.

21 Calverley PMA, Anderson JA, Celli B, et al. Salmeterol and fluticasone propionate and survival in chronic obstructive pulmonary disease. N Engl J Med 2007; 356: 775-789.

22 Quanjer PH, Tammeling GJ, Cotes JE, et al. Lung volumes and forced ventilatory flows: Report Working Party Standardization of Lung Function Tests, European Community for Steel and Coal. Official Statement of the European Respiratory Society. Eur Respir J 1993; 6: Suppl. 16, 5-40.

23 Cazzola M, MacNee W, Martinez FJ, et al. Outcomes for COPD pharmacological trials: from lung function to biomarkers. Eur Respir J 2008; 31: 416-468.

24 Eccles R. An explanation for the seasonality of acute upper respiratory tract viral infections. Acta Otolaryngol 2002; 122: 183-191.

25 Cold exposure and winter mortality from ischaemic heart disease, cerebrovascular disease, respiratory disease, and all causes in warm and cold regions of Europe. The Eurowinter Group. Lancet 1997; 349: 1341-1346.

26 UK Met Office. Healthy Outlook ${ }_{\mathbb{R}}$ COPD forecast alert service. www.metoffice.gov.uk/health/public/copd Date last updated: June 14, 2011. Date last accessed: October 21, 2011. 
27 Hajat S, Kovats RS, Lachowycz K. Heat-related and cold-related deaths in England and Wales: who is at risk? Occup Environ Med 2007; 64: 93-100.

28 Goodwin J, Taylor RS, Pearce VR, et al. Seasonal cold, excursional behaviour, clothing protection and physical activity in young and old subjects. Int J Circumpolar Health 2000; 59: 195-203.

29 Ko FWS, Tam W, Wong TW, et al. Temporal relationship between air pollutants and hospital admissions for chronic obstructive pulmonary disease in Hong Kong. Thorax 2007; 62: 780-785.

30 Yap FH, Ho PL, Lam KF, et al. Excess hospital admissions for pneumonia, chronic obstructive pulmonary disease, and heart failure during influenza seasons in Hong Kong. J Med Virol 2004; 73: 617-623.

31 Viboud C, Alonso WJ, Simonsen L. Influenza in tropical regions. PLoS Med 2006; 3: e89.

32 Wallace J, Nair P, Kanaroglou P. Atmospheric remote sensing to detect effects of temperature inversions on sputum cell counts in airway diseases. Envir Res 2010; 110: 624-32.

33 Bi P, Wang J, Hiller JE. Weather: driving force behind the transmission of severe acute respiratory syndrome in China? Int Med J 2007; 37: 550-554.

34 Dewan NA, Rafique S, Kanwar B, et al. Acute exacerbation of COPD. Factors associated with poor treatment outcome. Chest 2000; 117: 662-671.
35 Dales RE, Mehdizadeh A, Aaron SD, et al. Sex differences in the clinical presentation and management of airflow obstruction. Eur Respir J 2006; 28: 319-322.

36 Celli B, Vestbo J, Jenkins CR, et al. Sex differences in mortality and clinical expressions of patients with chronic obstructive pulmonary disease: the TORCH experience. Am J Respir Crit Care Med 2011; 183: 317-322.

37 Watson L, Schouten JP, Löfdahl C-G, et al. Predictors of COPD symptoms: does the sex of the patient matter?Eur Respir J 2006; 28: 311-318.

38 Garcia-Aymerich $\mathrm{J}$, Lange $\mathrm{P}$, Benet $\mathrm{M}$, et al. Regular physical activity reduces hospital admission and mortality in chronic obstructive pulmonary disease: a population based cohort study. Thorax 2006; 61: 772-778.

39 Coote K, Nicholls A, Atherton HC, et al. Mucociliary clearance is enhanced in rat models of cigarette smoke and lipopolysaccharideinduced lung disease. Exp Lung Res 2004; 30: 59-71.

40 Lalloo UG. The cough reflex and the "healthy smoker". Chest 2003; 123: 660-662

41 Wilkinson $\mathrm{P}$, Pattenden S, Armstrong A, et al. Vulnerability to winter mortality in elderly people in Britain: population based study. BMJ 2004; 329: 647.

42 McGarvey LP, John M, Anderson JA, et al. Ascertainment of causespecific mortality in COPD: operations of the TORCH Clinical Endpoint Committee. Thorax 2007; 62: 411-415. 